\title{
A Rare Case of Mixed Gonadal Dysgenesis
}

\author{
Doua K H Al homyani ${ }^{1}$, Sharifa Al Eissa ${ }^{2}$, Rushaid NA AL Jurayyan ${ }^{3}$, Nasir AM AL Jurayyan*4 and Abdulrahman A \\ Al Bassam ${ }^{5}$
}

${ }^{1}$ Department of pediatric, College of medicine, King Saud University, Saudi Arabia

${ }^{2}$ Department of pediatric, College of medicine, King Saud University, Saudi Arabia

${ }^{3}$ Radiology and medical imeging department, college of medicine, King Saud University, Saudi Arabia

${ }^{4}$ Professor and senior consultant pediatric endocrinologist, College of medicine, King Saud University, Saudi Arabia

${ }^{5}$ Department of Surgery, College of Medicine, King Saud University, Saudi Arabia

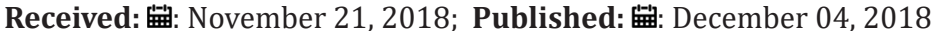

*Corresponding author: Nasir AM AL Jurayyan, Department of Pediatric, College of medicine, King Saud University, Saudi Arabia

\begin{abstract}
Mixed gonadal dysgenesis (45X/46XY and its variants) is a form of sex chromosome DSD (disorders of sex development). The clinical presentation of such patients is highly variable and mild variants may go unnoticed. Here we discuss a 13-year-old patient with mixed gonadal dysgenesis (45X/46 XY mosaicism) who was being reared as female, presented to us with virilizing symptoms and signs. The management issues in such patients were discussed.
\end{abstract}

Keywords: Mixed Gonadal Dysgenesis; Variant; Disorder of Sex Development

Abbreviation: DSD: Disorders of Sex Development; FISH: Fluorescence in Situ Hybridization; HCG: Human Chorionic Gonadotropin; MGD: Mixed Gonadal Dysgenesis; CIS: Carcinoma in Situ

\section{Introduction}

Mixed gonadal dysgenesis (45X/46XY and its variants) is a form of sex chromosome DSD (disorders of sex development). It is one of the most frequent causes of sexual ambiguity. It is a heterogeneous syndrome with a $45, \mathrm{X} / 46, \mathrm{XY}$ or $46, \mathrm{XY}$ karyotype, persistent müllerian duct structures, a dysgenetic testis, and a contralateral streak gonad. Functionally, the gonads were incompetent. Somatic features of turner syndrome, such as short stature, webbed neck, cubits valgus and gonadal failure may presented in these patient. Because of the presence of $\mathrm{Y}$ chromosome patient at risk of gonadal neoplasm, especially gonadoblastoma. So, gonadoectomy are involved. A multidisciplinary team including pediatric, endocrinologist, pediatric surgeon and psychologist should be involved. Indeed, in the ambiguous phenotypes, the decision regarding the assignment of sex must be taken as soon as possible [1-4].

\section{Case Report}

A 13-year-old girl was referred to the endocrine clinic for evaluation of short stature, and signs of virilization. She was born at 36 weeks of gestation with birth weight of $2 \mathrm{~kg}$ and history of oligohydrominous and clitoromegally which was corrected at that time. There was no history of maternal virilization during pregnancy or prenatal exposure to androgenic drugs. There was no family history of previously affected relatives or unexplained infant death. On exam, her height was $143 \mathrm{~cm}$ ( $<3 \mathrm{rd}$ percentile), body weight was $39.9 \mathrm{~kg}$ (25-50 percentile), BMI was $21.86 \mathrm{~kg} / \mathrm{m} 2$. She has low posterior hair line, ptosis, shield shape chest and cubits valgus. The rest of examination was normal. Tanner stage was prepubertal External genitalia showed clitromegally, with length of $4 \mathrm{~cm}$ and width of $2 \mathrm{~cm}$. Normal vaginal and urethral openings. Her karyotyping revealed $45 x, 46 x y+$ mar. SRY was positive by fluorescence in situ hybridization (FISH).

Human chorionic gonadotropin (HCG) stimulation test showed testosterone prestimulation $2.3 \mathrm{nmol} / \mathrm{L}$ and post stimulation $13.43 \mathrm{nmol} / \mathrm{L}$ indicating the presence of testicular tissue. LH:7.3IU/L, FSH:35.49IU/L and estradiol was less than 18.35 which go with hypergondotrophic hypogonadism. Magnetic resonance imaging MRI pelvis (Figure 1) showed: hypoplastic uterus and go- 
nadal dysgenesis and left gonadal tissue suggestive of testis. On pelvis laparoscopy, the uterus looked small, left gonad looked well developed while right gonad showed streak gonad and elongated clitoris, patient underwent bilateral gonadoectomy and clitroplasty. Histopathology gross description revealed left gonad ovarian like tissue attached with fallopian tube-like tissue, the ovary measure $2.0 \times 1.0 \times 1.0 \mathrm{~cm}$, the attached fallopian like tissue measures $2.5 \mathrm{~cm}$ in length, no tumor was seen. Right gonad consists of one piece of fallopian tube like tissue measuring $2.0 \mathrm{~cm}$ in length with attach tiny piece ovarian like tissue. Histological feature of left gonad consistent of infantile testicular tissue, Vas difference and collecting ducts were also seen, no intratubular germ cell neoplasia was detected (Figure 2A). Right gonad showed spermatic cord tissue with piece of vas deferens (Figure 2B). Pathologic findings were compatible to mixed gonadal digenesis.

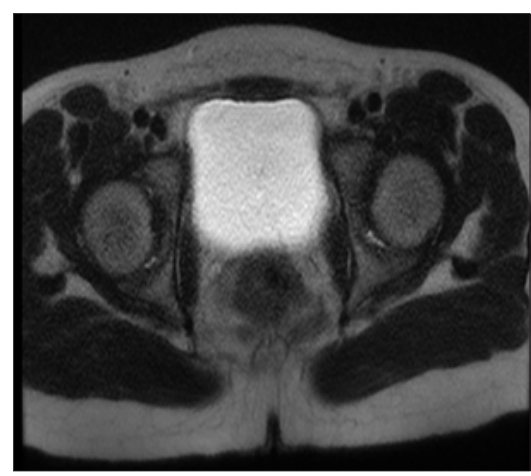

Figure 1: MRI pelvis showing hypoplastic uterus and gonadal dysgenesiS, left gonadal tissue suggestive of testis.

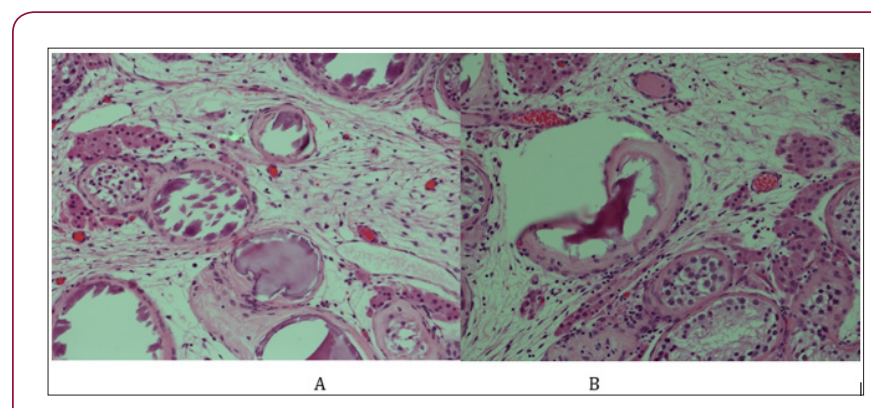

Figure 2: A: Left gonad consistent of infantile testicular tissue, Vas difference and collecting ducts were also seen, no intratubular germ cell neoplasia was detected. B: Spermatic cord tissue with a piece of vas deferencea.

\section{Discussion}

This patient is genetically Turner syndrome with karyotype of $45 x, 46 x y+$ mar, who was confirmed pathologically to form mixed gonadal dysgeneis. The positive SRY gene is an evidence of $Y$ material which was found in karyotyping. Mixed gonadal dysgenesis (MGD) comprises an heterogeneous group of diverse chromosomal, gonadal and phenotypic abnormalities which are characterized by the presence of a testis on one side and a contra- lateral streak or an absent gonad. Most patients have a 45,X/46,XY chromosomal mosaicism and germ cell tumors, such as gonadoblas- toma or dysgerminoma, which develop in about one third of patients with this syndrome [1,4]. Formation of the testis from the undifferentiated embryonic gonad depends on the presence of the short arm of the Y chromosome, containing SRY-sequences. Testosterone production stimulates development of the Wolffian system and induces male development of the external genitalia, failing which, differentiation proceeds along female lines and Müllerian structures are formed. There seems to be the necessity of a minimal amount of SRY to be present for the undifferentiated gonad to become a testis [3].

Apparently in our case, the threshold of SRY-containing cells $(68 \%)$ required for the development of the embryonic gonad into a testis was obviously adequate to enable complete differentiation of the right gonadinto a testis. The patients with 45,X/46, XY mosaicism are at a high risk for development of gonadal tumors. Carcinoma in situ (CIS) is thought to be a premalignant lesion leading to germ cell tumors [5,6]. Gonadoblastoma is the neoplasm most often found, and it can lead to malignant germinoma. The risk of this tumor is $15-20 \%$ and it increases with age. In the patients assigned a female gender role, the gonads should be removed, external genitalia should be repaired and oestrogen therapy should be initiated at the age of normal puberty. In patients assigned a male gender, all gonadal tissue except that which appears histologically normal and is in the scrotum should be removed, and prosthetic testes should be placed in the reconstructed scrotal sac, if appropriate. Even in the absence of evidence of testicular dysgenesis, close follow up is indicated, including a testicular biopsy at puberty and at age 20 to ascertain malignant potential [5,6] The need for androgen replacement therapy at adolescence depends on the capacity of the testes to secrete testosterone.

\section{Conclusion}

This is a 13-year old patient who presented with short stature, having bad virilizing symptoms, with karyotype being $45, \mathrm{X} / 46$, $\mathrm{XY}+$ mar mosaicism. MRI pelvis showed hypoplastic uterus and gonadal dysgenesis, left gonadal tissue suggestive of testes, no intratubular germ cell neoplasia was detected in histopathology. Pathologic findings were compatible to mixed gonadal dysgeneis. Bilateral gonadoectomy and clitroplasty were done for her. Correct diagnosis and management in this patient needed a multiple disciplinary team approach (pediatric endocrinologist, pediatric surgeon, pathologist and psychologist).

\section{Acknowledgement}

The authors would like to thank Mr. Abdulrahman $\mathrm{N} \mathrm{Al}$ Jurayyan for his help in preparing this manuscript and extend their thanks and appreciation to the college of medicine research Centre, Deanship of scientific research King Saud University, Riyadh, Saudi Arabia.

\section{References}

1. Mendez JP, Ulloa Aguirre A, Kofman Alfaro S, Mutchinick O, Fernandez del Castillo C, et al. (1993) Mixed gonadal dysgenesis: clinical, cytogenetic, endocrinological, and histopathological findings in 16 patients. Am J Med Genet 46(3): 263-267.

2. Sperling MA (2007) Pediatric endocrinology. 3rd ed. Philadelphia: Saunders/Elsevier pp. 667. 
3. HSU LY (1994) Phenotype/karyotype correlations of Y chromosome aneuploidy with emphasis on structural aberrations in postnatally diagnosed cases. Am J Med Genet 53(2): 108-140.

4. Robboy SJ, Miller T, Donahoe PK, Jahre C, Welch WR, et al. (1982) Dysgenesis of testicular and streak gonads in the syndrome of mixed gonadal dysgenesis: perspective derived from a clinicopathologic analysis of twenty-one cases. Hum Pathol 13(8): 700-716.

\section{ISSN: 2574-1241}

DOI: 10.26717/BJSTR.2018.11.002143

Nasir AM AL Jurayyan. Biomed J Sci \& Tech Res

CC (P) This work is licensed under Creative

Submission Link: https://biomedres.us/submit-manuscript.php
5. Muller J, Ritzen EM, Ivarrsson SA, Rajpert De Meyts E, NorjavaaraE, et al. (1999) Management of males with 45,X/46,XY Gonadal dysgenesis. Horm Res 52(1): 11-14.

6. Müller J, Skakkebaek NE, Ritzén M, Plöen L, Petersen KE (1985) Carcinoma in situ of the testis in children with $45, \mathrm{X} / 46, \mathrm{XY}$ gonadal dysgenesis. J Pediatr 106(3): 431-436.

$\begin{array}{ll}\text { BIOMEDICAL } & \text { Assets of Publishing with us } \\ \text { RESEARCHES } & \text { - Global archiving of articles } \\ \text { - Immediate, unrestricted online access }\end{array}$

